\title{
Retrospective trial of influence of atrial septal defect closure on manifestation and prognosis of migraine attacks in pediatric patients
}

\author{
YS Lizunou ${ }^{1 *}$, AS Fedulov', EU Procenko², DB Goncharik², UM Chesnov² \\ From The European Headache and Migraine Trust International Congress \\ London, UK. 20-23 September 2012
}

\section{Introduction}

Previous studies found a presence of atrial septal defect (ASD) in some cases of patients with migraine and respective efficacy of ASD closure as a treatment of migraine.

\section{Purpose}

To study an influence of atrial septal defect (ASD) closure on clinical course of migraine in children.

\section{Methods}

Interviewing was conducted in 75 pediatric patients (age 10 to 18 years) operated for ASD (surgical or occluder implantation) in Children's National Cardiology Center «RNPC Cardiology» ( $\mathrm{n}=75$, male 31 , female 44, mean age $=15.2 \pm 3.4$ years) to identify their migraine attacks, migraine specific clinical pictures (evaluation of intensity, location of pain, aura), differentiate migraine pain from other types of headache.

\section{Results}

Before ASD closure migraine was presented in 8 patients (10.67\%): 2 males (25\%), 6 females (75\%). Nomplete disappearance of migraine after operation was remarked in 2 patients $(25 \%)$. Reduction of migraine symptoms was found in other 6 patients (75\%). Reduction/disappearance of migraine within 1-7 days after ASD closure was observed in 7 patients $(87.5 \%)$ and within 7 to 14 days in 1 patient (12.5\%). Noteworthy, in 6 patients $(6.67 \%)$ migraine debut was observed in the early postoperative period (after ASD closure). In all 5 patients migraine starts early in postoperative period ( 1 to 3 days). Migraine was transient in all 5 patients (100\%) persisting for 7-14 days to 3.5 years.

\section{Conclusions}

The study indicate that closure of ASD in children effectively reduced migraine in most patients (77.8\%), and completely eliminated migraine attacks in other $22.2 \%$ of cases, most often in early postoperative period (88.9\%). Most often migraine decreased / disappeared in the period 1-14 days after ASD closure. Probability of migraine reduction /disappearance $>14$ days after ASD closure is minimal. In some patients $(6.8 \%)$ debut of migraine was observed early (within first 3 days) in postoperative period but migraine symptom were transient in all patients $(100 \%)$.

\section{Author details}

'Belarussian State Medical University, Belarus. ${ }^{2}$ Republican Research and Clinical Centre "Cardiology", Belarus.

Published: 21 February 2013

\section{References}

1. Campbell M: Natural history of atrial septal defect. Br Heart J 1970, 32:820-826.

2. Rundek T, Elkind MS, Di Tullio MR, Carrera E, Jin Z, Sacco RL, Homma S: Patent foramen ovale and migraine: a cross-sectional study from the Northern Manhattan Study (NOMAS). Circulation 2008, 118:1419-1424.

3. Azarbal B, Tobis J, Suh W, Chan V, Dao C, Gaster R: Association of interatrial shunts and migraine headaches: impact of transcatheter closure. J Am Coll Cardiol 2005, 45:489-492.

doi:10.1186/1129-2377-14-S1-P101

Cite this article as: Lizunou et al:: Retrospective trial of influence of atrial septal defect closure on manifestation and prognosis of migraine attacks in pediatric patients. The Journal of Headache and Pain 2013 14(Suppl 1):P101. 